\title{
Resistance of thermally modified and pressurized hot water extracted Scots pine sapwood against decay by the brown-rot fungus Rhodonia placenta
}

\author{
Michael Altgen ${ }^{1} \cdot$ Suvi Kyyrö ${ }^{1}$. Olli Paajanen ${ }^{2} \cdot$ Lauri Rautkari $^{1}$
}

Received: 19 May 2019 / Published online: 7 December 2019

(c) The Author(s) 2019

\begin{abstract}
The thermal degradation of wood is affected by a number of process parameters, which may also cause variations in the resistance against decay fungi. This study compares changes in the chemical composition, water-related properties and decay resistance of Scots pine sapwood that was either thermally modified (TM) in dry state at elevated temperatures $\left(\geq 185^{\circ} \mathrm{C}\right)$ or treated in pressurized hot water at mild temperatures $\left(\leq 170{ }^{\circ} \mathrm{C}\right)$. The thermal decomposition of easily degradable hemicelluloses reduced the mass loss caused by Rhodonia placenta, and it was suggested that the cumulative mass loss is a better indicator of an actual decay inhibition. Pressurized hot water extraction (HWE) did not improve the decay resistance to the same extent as TM, which was assigned to differences in the wood-water interactions. Cross-linking reactions during TM caused a swelling restraint and an effective reduction in moisture content. This decreased the water-swollen cell wall porosity, which presumably hindered the transport of degradation agents through the cell wall and/or reduced the accessibility of wood constituents for degradation agents. This effect was absent in hot water-extracted wood and strong decay occurred even when most hemicelluloses were already removed during HWE.
\end{abstract}

\section{Introduction}

Most European wood species have a low resistance against the decomposition by decay fungi, which shortens their service life in exterior applications. Traditionally, this has been overcome by impregnating wood products with preservatives that are toxic to fungi. However, concerns about their toxicity for humans and the environment have led to the development of alternative protection techniques (Hill 2006). It has long been recognized that the partial thermal degradation of wood by the exposure to elevated temperatures enhances its resistance to decay fungi without the use of biocides (Hakkou et al. 2006). However, the underlying modes of action in increasing the wood's resistance against fungal decay by heat exposure as well as the link between these modes of

Michael Altgen

michael.altgen@aalto.fi

1 Department of Bioproducts and Biosystems, Aalto University, P.O. Box 16300, 00076 Aalto, Finland

2 Mikpolis Research Unit, South Eastern Finland University of Applied Sciences, P.O. Box 68, 50101 Mikkeli, Finland action and the various thermal degradation reactions are still subjects for research (Thybring 2013; Ringman et al. 2016).

Thermal modification (TM) of solid wood explicitly aims at improving the decay resistance to enhance the service life of wood products. Although various TM processes exist in Europe, most of them treat the wood in the temperature range between 160 and $240{ }^{\circ} \mathrm{C}$ for several hours, while the wood is in a relatively dry state. Water vapor is a common shielding gas in such TM processes (Militz and Altgen 2014). In contrast, pressurized hot water extraction (HWE) of wood does not aim at improving the decay resistance, but at removing hemicelluloses as substrates for bioethanol production (Kemppainen et al. 2012) or for conversion into high-value added products (Ebringerová and Heinze 2000). HWE is performed in pressurized hot water in a wide temperature range between 120 and $240{ }^{\circ} \mathrm{C}$, at treatment durations reaching from a few seconds to several hours (Sella Kapu and Trajano 2014). The solid residue can be used as a feedstock for the pulp and paper production (Yoon and Van Heiningen 2008), but may also be utilized as construction material and in engineered wood products, such as oriented strand boards (Sattler et al. 2008), particleboards (PelaezSamaniego et al. 2014), or wood polymer composites (Hosseinaei et al. 2012). 
Both heat treatment (HT) techniques, TM and HWE, induce a great variety of thermal degradation reactions within the wood cell wall depending on the process conditions applied. Among the cell wall components, hemicelluloses and non-crystalline cellulose are particularly sensitive to HT. Their degradation starts with the hydrolytic cleavage of the glycosidic bonds and proceeds with the dehydration of the sugars to furan-type derivatives, i.e. furfural and hydroxymethylfurfural (HMF) from pentoses and hexoses, respectively (Garrote et al. 1999). Hemicellulose degradation products are removed from the wood by either diffusing into the process water during HWE, or by vaporization during TM. This causes a loss in wood dry mass and an accumulation of crystalline cellulose and lignin in the wood residue. Simultaneous to such compositional changes and covalent bond cleavage, re-polymerization reactions involving residual cell wall polymers and formed degradation products (e.g. furfural and HMF) result in the formation of additional covalent bonds and cross-links within the cell wall of heat-treated wood (Tjeerdsma et al. 1998; Garrote et al. 1999). These degradation reactions are interrelated and occur simultaneously. Therefore, the assignment of wood property changes to specific, heat-induced cell wall changes is difficult.

In laboratory decay tests with basidiomycetes, Rhodonia placenta often causes a comparably high mass loss for TM-wood (Welzbacher and Rapp 2007; Metsä-Kortelainen and Viitanen 2009). Therefore, R. placenta is often used as a test fungus for the investigation of the modes of action in increasing the decay resistance by TM (Mohareb et al. 2012; Ringman et al. 2016). $R$. placenta causes brown-rot decay that degrades the cell wall carbohydrates and results in the accumulation of (oxidized) lignin in the wood residue (Winandy and Morrell 1993; Kirk and Highley 1973). The decay process of brown-rot fungi is best known from studies on Gloeophyllum trabeum (Goodell et al. 1997; Arantes et al. 2011), but certain aspects of this process have also been verified for other brown-rot fungi, including $R$. placenta (Hyde and Wood 1997; Cohen et al. 2002; Arantes et al. 2011; Zhang et al. 2016; Goodell et al. 2017). Brownrot fungi have developed a non-enzymatic decay system that is based on low molecular weight oxidants and chelators to overcome the limitation of enzymes to penetrate the sound wood cell wall (Zhang et al. 2016; Goodell et al. 2017). By using iron reductants, oxalic acid and hydrogen peroxide, they initiate the Fenton's reaction within the wood cell wall remote from the fungal hyphae, which forms hydroxyl radicals that depolymerize the cell wall polymers (Goodell et al. 1997; Hammel et al. 2002; Arantes et al. 2012). Previously, it was expected that this non-enzymatic decay system opens up the cell wall for enzymes to enter at a later decay stage (Flournoy et al. 1993). However, recent studies suggest a staggered mechanism, during which the non-enzymatic degradation of cell wall carbohydrates results in the diffusion of oligosaccharides into the cell lumen, where they can be accessed by fungal enzymes (Zhang et al. 2016; Goodell et al. 2017).

A higher resistance of thermally modified wood (TMwood) against decay by $R$. placenta does not necessarily imply that the fungus no longer degrades the wood. Instead, TM slightly prolongs the time until fungal degradation starts (Ringman et al. 2016) and decreases the rate at which mass loss by the fungus progresses over time in laboratory tests significantly (Ringman et al. 2016; Wang et al. 2018). The decay rate is not influenced by a fungicidal effect of remaining thermal degradation products, because their extraction prior to decay testing does not have a significant effect on the recorded mass loss by fungal decay (Hakkou et al. 2006; Mohareb et al. 2012). It is also unlikely that structural changes in TM-wood prevent decay by interfering with the recognition of cell wall polymers by enzymes, because the non-enzymatic decay systems applied by decay fungi do not rely on substrate recognition to degrade cell wall polymers (Ringman et al. 2014). Furthermore, the expression of genes for different enzymes of $R$. placenta does not differ between unmodified and TM-wood when analyzed at the same decay stage (Ringman et al. 2016). Instead, recent studies suggest the reduced moisture content (MC) to be the main cause for the enhanced decay resistance of wood after chemical or thermal modification (Thybring 2013; Li et al. 2017; Thybring et al. 2018). Reducing the MC has been suggested to hinder the diffusion of ions (and other chemical species emitted by the fungi) through the cell wall (Hosseinpourpia and Mai 2016; Zelinka et al. 2016), which is an integral part of the chelator-mediated Fenton's reaction of brown-rot fungi (Kirker et al. 2017). However, in contrast to chemical modifications, the reduction in MC by TM is accompanied by the removal of hemicelluloses. Since easily degradable hemicelluloses are the primary nutrient source for decay fungi, their removal is likely to affect the decay rate that is determined in laboratory tests (Hakkou et al. 2006).

In this study, the effect of TM and HWE on the decay by $R$. placenta was compared to investigate the modes of action in increasing the decay resistance of Scots pine sapwood by heat exposure. In a previous study, it has been demonstrated that HWE at mild temperatures $\left(\leq 170{ }^{\circ} \mathrm{C}\right)$ removes similar amounts of hemicelluloses to TM at elevated temperatures $\left(\geq 180^{\circ} \mathrm{C}\right.$ ), but differs greatly in the ability to reduce MC and swelling of the wood (Altgen et al. 2018b). It is hypothesized that, at the same amount of hemicellulose removal, a lower reduction in MC and an increased swelling of HWE-wood results in a lower decay resistance compared to TM-wood. 


\section{Materials and methods}

\subsection{Material}

Samples with dimensions of $15 \times 25 \times 50 \mathrm{~mm}^{3}(\mathrm{R} \times \mathrm{T} \times \mathrm{L})$ were cut from kiln-dried boards of Scots pine (Pinus sylvestris $\mathrm{L}$.) sapwood. For the determination of the resistance against Rhodonia placenta, the growth rings were oriented in $45^{\circ}$ to the tangential surface. For the determination of moisture content and swelling, the growth rings were oriented in parallel to the tangential surface. All samples were clear of heartwood, knots and defects.

\subsection{Heat treatments}

Prior to HT, the initial dry mass and dry dimensions were determined after oven-drying using a temperature sequence of $40,60,80$ and finally $103{ }^{\circ} \mathrm{C}$, with each temperature held for ca. $24 \mathrm{~h}$. TM and HWE were performed as described previously (Altgen et al. 2018a). During TM, oven-dry samples were treated in an oven with superheated steam at atmospheric pressure. The temperature was raised until reaching a treatment temperature of either 185, 200, 215 or $230{ }^{\circ} \mathrm{C}$, which was held for $3 \mathrm{~h}$. During HWE, watersaturated samples were heated in pressurized hot water (solid:liquid 1:20 by weight) in closed vessels of an air bath digester. Treatment temperatures of $125,140,155$ or $170{ }^{\circ} \mathrm{C}$ were applied and held for $2 \mathrm{~h}$. All samples were subjected to a water leaching procedure for 14 days with daily water changes. After water leaching, the dry mass was recorded as described above. The mass loss caused by HT (in \%) was determined based on the difference between the dry mass before HT and the dry mass after HT and water leaching, which was related to the dry mass before HT.

\subsection{Chemical composition}

Four samples per sample group (HT technique and peak temperature) after the HT and four samples per sample group after the decay test (see 2.5) were milled and mixed in a Wiley mill. The particles were sieved and the fraction between 0.2 and $0.4 \mathrm{~mm}$ was extracted with $200 \mathrm{ml}$ acetone in a Soxhlet apparatus for $6 \mathrm{~h}$. The determination of carbohydrates and lignin was performed on the extracted samples according to the analytical procedure (NREL/TP-510-42618) issued by the US National Renewable Energy Laboratory (Sluiter et al. 2012). Carbohydrates were determined by high performance anion exchange chromatography with pulse amperometric detection (HPAEC-PAD) in a Dionex ICS-3000 column. The lignin content was determined gravimetrically as the acid-insoluble fraction after drying at $103{ }^{\circ} \mathrm{C}$ for $12 \mathrm{~h}$. Ash content was determined according to
TAPPI 211 on-02 (2002) by exposing oven-dried samples to $525{ }^{\circ} \mathrm{C}$ for $5 \mathrm{~h}$. All analyses were performed in duplicate. The amount of hemicelluloses was estimated by the sum of all detected sugars except glucose. The loss of hemicelluloses and glucose during the decay test was estimated by the differential hemicellulose to lignin ratio and the differential glucose to lignin ratio, respectively, which were calculated according to Eqs. 1 and 2:

$\Delta$ Hem $/$ Lig ratio $=\frac{\text { Hem (\%)after HT }}{\text { Lig (\%)after HT }}-\frac{\text { Hem (\%)after decay }}{\text { Lig (\%)after decay }}$

$\Delta$ Gluc $/$ Lig ratio $=\frac{\text { Glu (\%)after HT }}{\text { Lig (\%)after HT }}-\frac{\text { Glu (\%)after decay }}{\text { Lig (\%)after decay }}$

where Hem (\%), Lig (\%) and Glu (\%) refer to the percentages of hemicelluloses, lignin and glucose, respectively.

\subsection{Water vapor uptake and swelling}

The water vapor adsorption was measured on sections $\left(15 \times 25 \times 5 \mathrm{~mm}^{3} ; \mathrm{R} \times \mathrm{T} \times \mathrm{L}\right)$ that were cut from the samples $\left(15 \times 25 \times 50 \mathrm{~mm}^{3}\right)$. The sections were oven dried at $103{ }^{\circ} \mathrm{C}$ for $24 \mathrm{~h}$ and cooled down in a desiccator over silica gel to determine the dry mass and dimensions before placing them in a desiccator above deionized water. The desiccator was stored in a room conditioned at $20{ }^{\circ} \mathrm{C}$. The change in mass by the adsorption of water was measured regularly within 121 days of conditioning. A balance with a precision of $0.1 \mathrm{mg}$ was used for the mass determination and the samples were measured in a random order. After the mass changes remained constant, the sample dimensions were recorded in addition to the sample mass. Finally, the samples were submersed in deionized water for several days and the dimensions were recorded again after full water saturation. Swelling was calculated as the difference in the cross-sectional area $(\mathrm{R} \times \mathrm{T})$ between the moist and the dry state, which was related to the dry cross-sectional area.

\subsection{Resistance against Rhodonia placenta}

Resistance against Rhodonia placenta (Fr.) Niemelä, KH Larsson and Schigel (strain DSM 3088; Leibniz Institute DSMZ-German Collection of Microorganisms and Cell Cultures, Braunschweig, Germany) was tested based on CEN/ TS 15083-1 (2005) on an agar-malt medium. Thirty reference samples (unmodified Scots pine sapwood) were used, while the heat-treated samples were tested with ten replicates per sample group (HT process and peak temperature). All samples were conditioned at $20{ }^{\circ} \mathrm{C}$ and $65 \%$ RH until reaching equilibrium mass prior to the decay test. The samples were wrapped in aluminum foil before the sterilization 
was performed in an autoclave at $121{ }^{\circ} \mathrm{C}$. Two samples from the same sample group were placed in each test flask for incubation. After 16 weeks of incubation with $R$. placenta at $20{ }^{\circ} \mathrm{C}$ and $70 \% \mathrm{RH}$, the mycelium at the sample surfaces was removed carefully before the mass was determined after oven-drying at $103{ }^{\circ} \mathrm{C}$ for $24 \mathrm{~h}$. The $\mathrm{MC}$ increase during incubation (\%-points) and the mass loss by $R$. placenta (\%) were calculated according to Eqs. 3 and 4, respectively:

$$
\begin{aligned}
& \text { MC increase }=M C \%_{\text {after }}-\mathrm{MC}_{\text {before }} \\
& =\left(\frac{\mathrm{m}_{3}-\mathrm{m}_{4}}{\mathrm{~m}_{1}}-\frac{\mathrm{m}_{2}-\mathrm{m}_{1}}{\mathrm{~m}_{1}}\right) \times 100 \%,
\end{aligned}
$$

Mass loss by R.placenta $=\frac{\mathrm{m}_{1}-\mathrm{m}_{4}}{\mathrm{~m}_{1}} \times 100 \%$,

where $m_{1}$ is the oven-dry mass before decay, $m_{2}$ is the conditioned mass before decay, $\mathrm{m}_{3}$ is the mass after incubation and removal of fungal mycelium, and $\mathrm{m}_{4}$ is the oven-dry mass after decay (all in g). The calculated MC after incubation $\left(\mathrm{MC} \%_{\mathrm{after}}\right)$ is unaffected by a reduction of the reference mass by fungal decay, because the water mass $\left(\mathrm{m}_{3}-\mathrm{m}_{4}\right)$ is related to the dry mass before the incubation.

\section{Results and discussion}

\subsection{Changes in chemical composition and hygroscopicity by heat-treatment}

The results of the chemical composition analysis showed a decreased percentage of hemicellulose sugars and an increased percentage of lignin compared to the reference after HT (Fig. 1). However, the decrease in hemicellulose sugars and the increase in lignin as a function of the mass loss by HT was larger after TM than after HWE. Since the samples were subjected to a water-leaching procedure prior to the determination of the dry mass after HT, residual degradation products in the wood did not cause an underestimation of the mass loss by HT. The low amount of residual degradation products was confirmed by the results of the Soxhlet extraction with acetone, which yielded extraction contents below $2.3 \%$. Therefore, the differences in chemical composition as a function of mass loss are not a result of inadequate mass loss determination. Instead, they coincide with previous studies by the authors that evidenced an effective removal of hemicelluloses due to wood auto-hydrolysis during HWE, but a lack of repolymerisation reactions that result in the formation of pseudo-lignin (Altgen et al. 2018a). Repolymerisation reactions involving carbohydrate degradation products, i.e. furan-type derivatives, and lignin may be more facile during TM under dry heat conditions and elevated temperatures than during HWE at mild temperatures $\left(\leq 170^{\circ} \mathrm{C}\right)$. The presence of water and the mild temperatures during HWE may hinder the dehydration of sugars to furan-type derivatives (Altgen et al. 2018a) and/ or cause the diffusion of sugars and furan-type derivatives from the wood cell walls into the process water (Altgen et al. 2018b).

The change in the sugar composition as a function of the mass loss by HT shows a similar pattern for both HT techniques (Fig. 2). The increase in glucose content indicates the accumulation of cellulose during HT. Arabinose and galactose, which are mainly found at the side chains of hemicelluloses, were removed more rapidly than mannose and xylose, which build the main chain of the hemicelluloses in softwoods (Winandy 2017). The arabinose content already decreased to less than $50 \%$ of its initial content when reaching a mass loss by HT of about $5 \%$. Less than $15 \%$ of the initial arabinose content was found in the solid residue when the mass loss by HT exceeded $10 \%$. Rhamnose is not displayed in Fig. 2, because of its low contents near the detection limit. The only notable difference between the HT techniques was the larger loss in xylose than in mannose content during TM (Fig. 2 a), while HWE resulted in a larger loss in mannose than in xylose content when reaching a mass loss by HT above 15\% (Fig. 2b).

Repolymerisation reactions during TM have been suggested to enhance the cross-linking of the cell wall matrix to cause an efficient MC reduction (Tjeerdsma et al. 1998; Repellin and Guyonnet 2005; Rapp et al. 2008). In line with this hypothesis, TM- and HWE-wood samples differed regarding their moisture uptake during conditioning over water in a desiccator (Fig. 3). The rate at which moisture

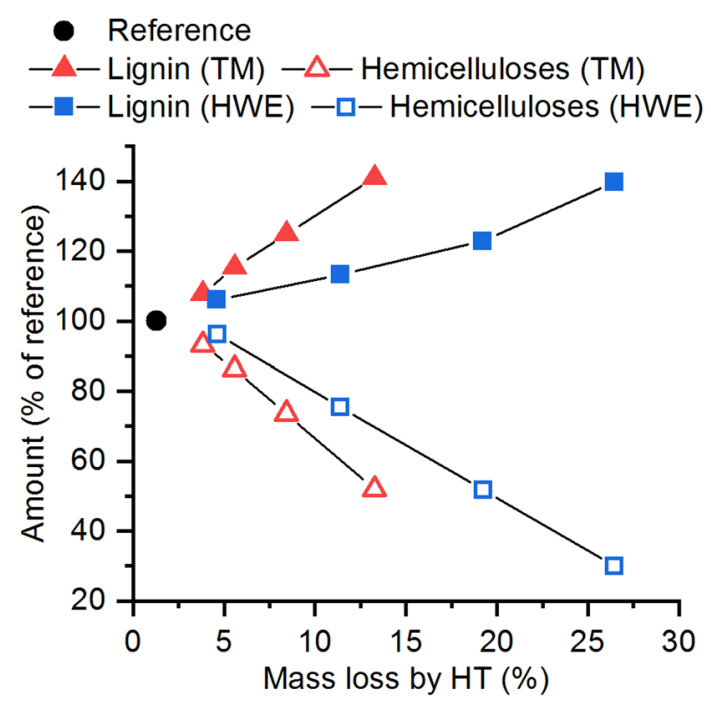

Fig. 1 Changes in the amount of lignin and hemicellulose sugars (sum of all sugars except glucose) as a function of the mass loss by heat treatment 


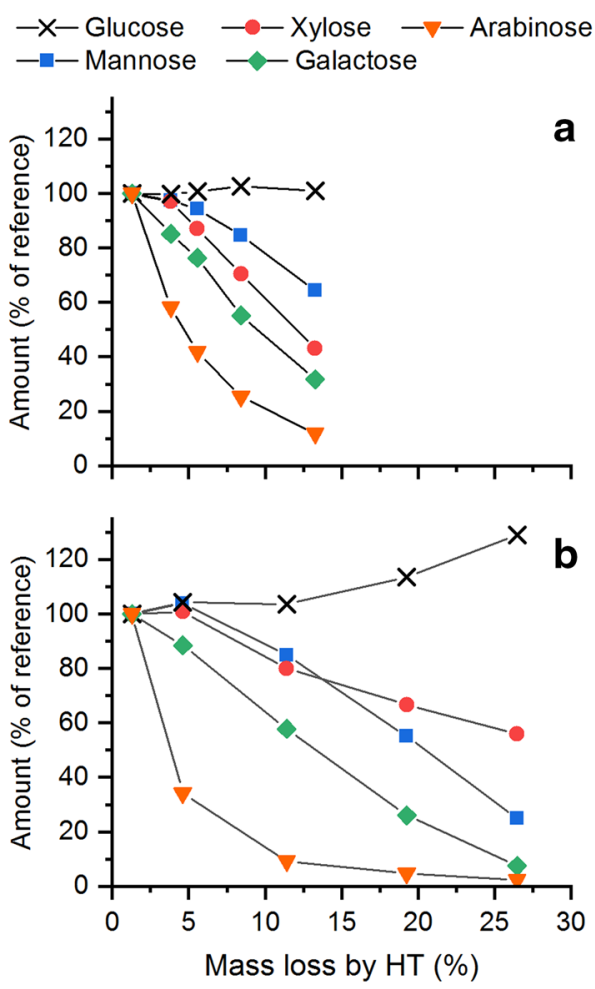

Fig. 2 Changes in the amount of sugars (\% of initial) as a function of the mass loss caused by heat treatment (\%) for TM-wood (a) and HWE-wood (b)

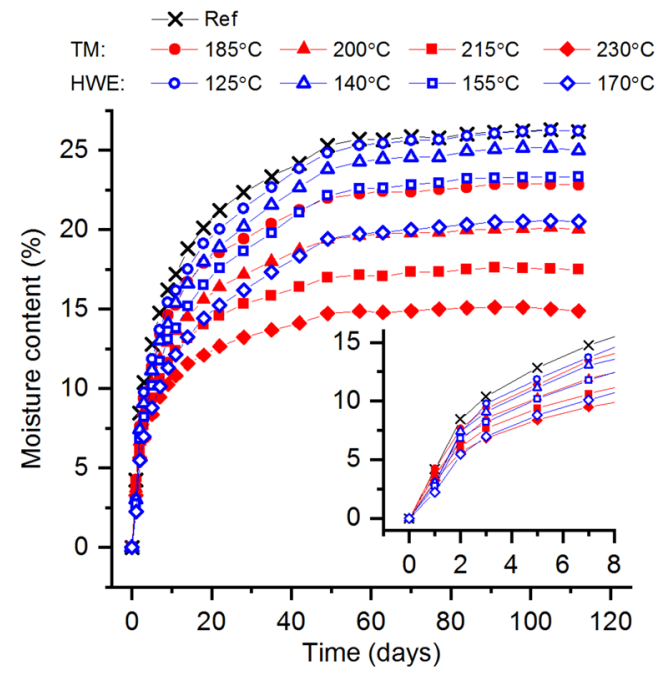

Fig. 3 Change in moisture content $(\% ; N=4)$ during storage over water as a function of the duration (days). The moisture content changes from day 0 to day 8 are shown as inset

was taken up decreased with increasing HT temperature. However, while the moisture uptake was in a similar range for HWE- and TM-wood within the first few days of exposure, HWE-wood samples took up moisture at a faster rate during longer exposure times than TM-wood samples. Samples that were treated at $125^{\circ} \mathrm{C}$ in pressurized hot water even reached the moisture content of the reference samples after approximately 70 days. Nonetheless, a delay in the uptake of water was also recorded after $\mathrm{HWE}$ at higher temperatures. After HWE at $170{ }^{\circ} \mathrm{C}$, it took 70 days until a MC of $20 \%$ was recorded, which took only 18 days for the reference samples. With time intervals of 7 days between the measurements, no difference in the duration required to reach an equilibrium mass could be observed between the different sample groups.

Besides differences in the $\mathrm{MC}$ between the sample groups over time, differences were also found when displaying the final $\mathrm{MC}$ at the end of the conditioning test as a function of the mass loss by HT (Fig. 4a). TM caused a much stronger decrease in the final MC compared to HWE, which is in line with previous results (Altgen et al. 2018b). The lowest $\mathrm{MC}$ was measured after $\mathrm{TM}$ at $230{ }^{\circ} \mathrm{C}$, which resulted in an MC of ca. $15 \%$ at a mass loss by HT of ca. $13 \%$. In contrast, HWE at $170{ }^{\circ} \mathrm{C}$ caused a larger mass loss (ca. 26\%), but the final MC still exceeded $20 \%$.

Interestingly, HWE-samples showed an increase in swelling compared to the reference samples, despite a decrease in $\mathrm{MC}$ after conditioning over water (Fig. 4b). However, room
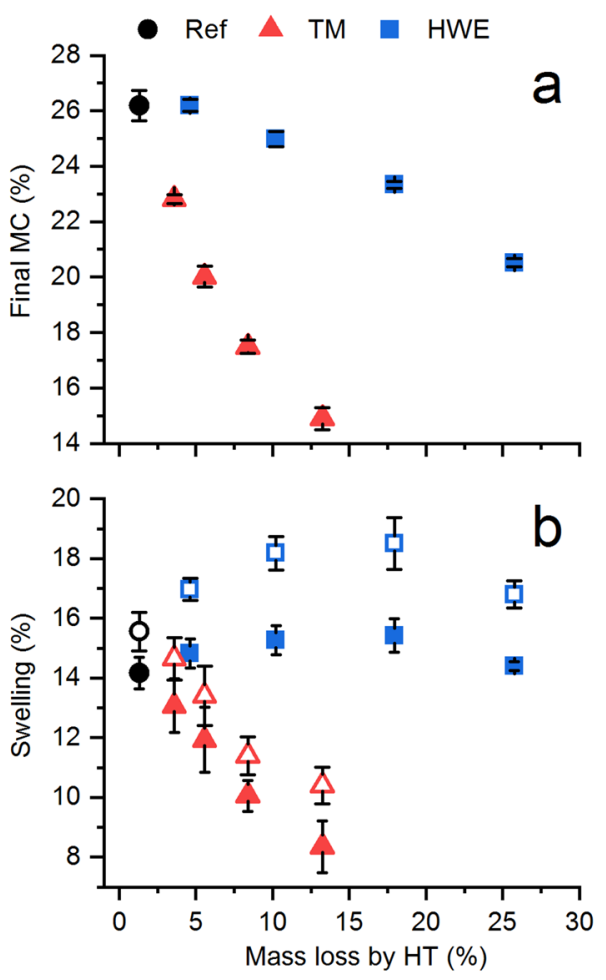

Fig. 4 Final MC (in \%, a) after conditioning over water as well as swelling (in \%, b) after conditioning over water (closed symbols) and after water saturation (open symbols) as a function of the mass loss during heat treatment $(\%)$. $(N=4$; error bars represent the standard deviation) 
temperature fluctuations prevent the attainment of saturated water vapor conditions in a desiccator that contains deionized water (Strømdahl 2000). Therefore, the samples were additionally soaked in liquid water, which resulted in a general increase in swelling. The increase in swelling from the conditioned to the water-saturated state was approximately the same for reference and TM-wood, but a larger increase in swelling was recorded for HWE wood. The latter reached a maximum of $18.5 \%$ at a mass loss by HT of ca. $18 \%$. It is speculated that while the removal of hemicelluloses decreased the amount of sorption sites for water, it may have also eased the expansion of the cell wall nanopores to create swelling. In contrast, enhanced cross-linking of the cell wall matrix by repolymerisation reactions during TM may have caused an effective swelling restraint. Thereby, water molecules could no longer access space that was previously occupied by hemicelluloses (Altgen et al. 2018b).

\subsection{Resistance against Rhodonia placenta}

The results of the decay test are in line with the authors` hypothesis that HWE of wood at mild temperatures removes similar amounts of hemicelluloses, but does not cause swelling restraint and, therefore, does not enhance the decay resistance to the same extent as TM. Both HT techniques affected the mass loss caused by $R$. placenta as well as the increase in MC after 16 weeks of incubation (Fig. 5).

During the incubation, the $\mathrm{MC}$ increased for all sample groups (Fig. 5a). The course of the increase in $\mathrm{MC}$ as a function of the mass loss by HT strongly resembled the results of the change in swelling shown in Fig. 4b, hence a lower increase in MC was evident in TM-wood compared to HWE-wood. This may suggest a restraint in the moisture uptake of TM-wood during the incubation with $R$. placenta, in line with the swelling restraint in TM-wood described in Sect. 3.1. However, fungal decay is a major cause for an increase in wood MC. In this study, the dry sample mass prior to the incubation with $R$. placenta was used as reference mass for the calculation of the MC after decay. Therefore, the increase in MC was not caused by a decrease in the reference mass by fungal decay, but by an increase in the water mass. Nonetheless, decay fungi transport liquid water into the wood structure (Stienen et al. 2013; Meyer and Brischke 2015) and the decomposition of cell wall
Fig. 5 Results after 16 weeks of incubation with Rhodonia placenta: Increase in moisture content after incubation (\%-points) as a function of the mass loss by heat-treatment (\%, a); Cumulative mass loss by heat-treatment (\%) and by Rhodonia placenta $(\%)$ as a function of the applied temperature (in ${ }^{\circ} \mathrm{C}$ ) and $\mathrm{HT}$ technique (b); Mass loss by Rhodonia placenta (\%) as a function of the mass loss by heat-treatment (in \%,c) and as a function of the amount of hemicelluloses prior to the decay test (in \% of reference; d). Error bars represent the standard deviation

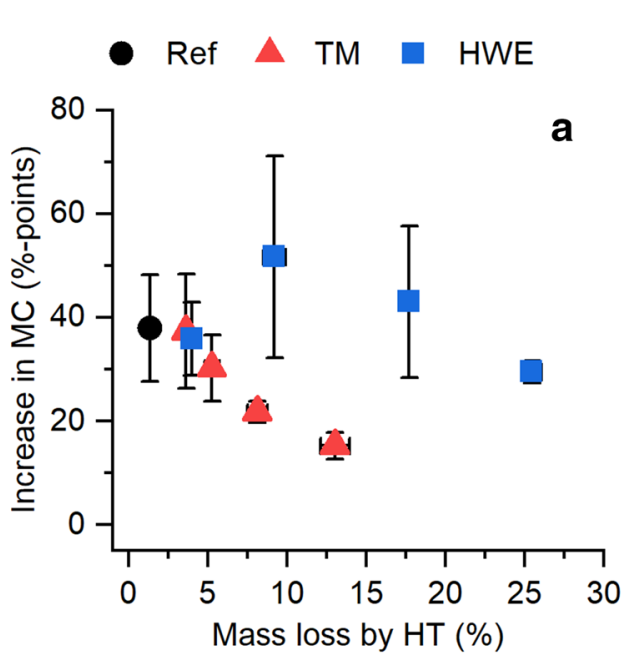

Mass loss by R. placenta Mass loss by heat-treatment
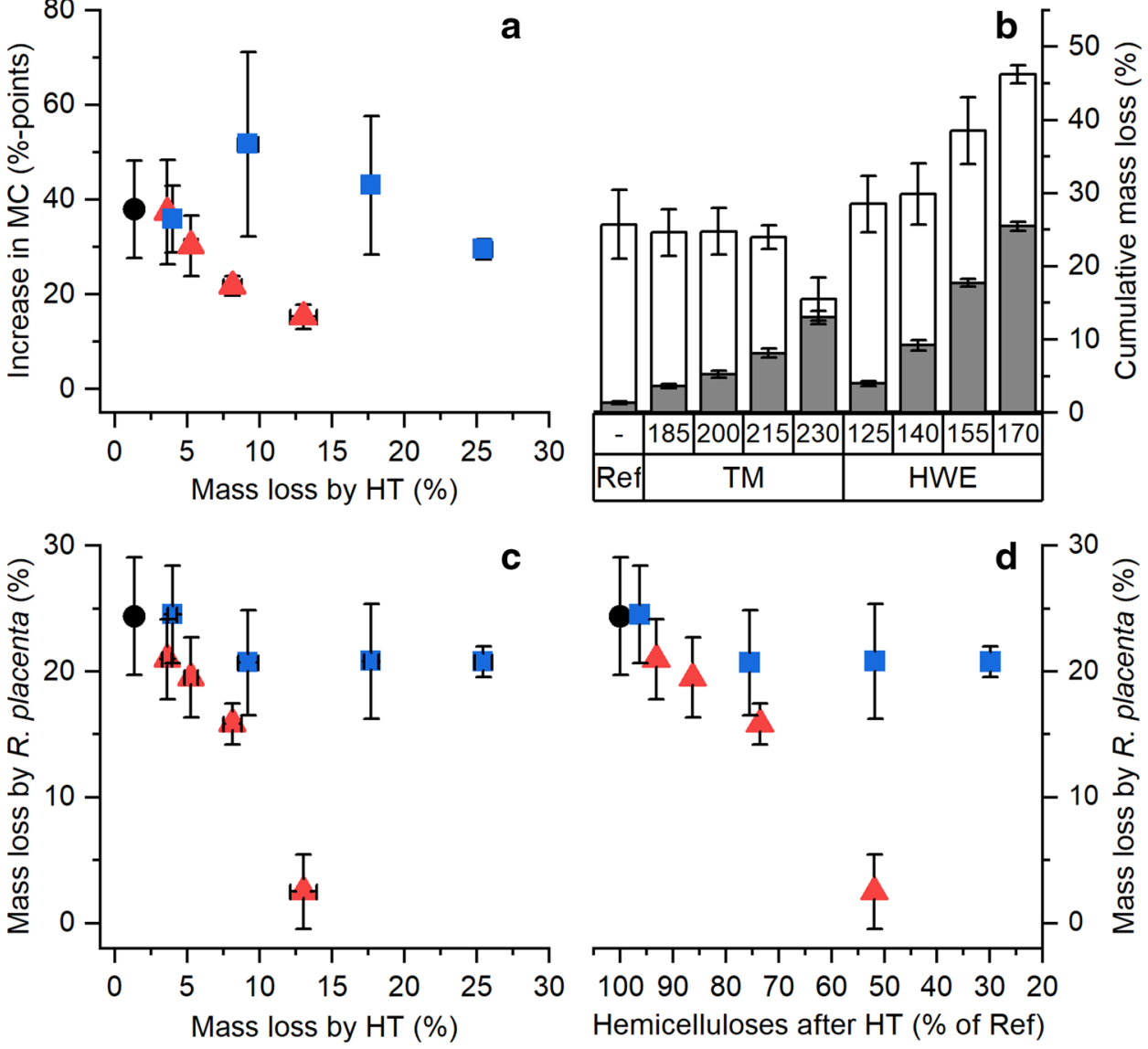
constituents generates water (Ammer 1963). Therefore, a lower MC increase may also be the outcome, and not only the cause, of a higher decay resistance of TM-wood.

The mass loss by $R$. placenta decreased below the reference value for both HT techniques (Fig. 5b). Removal of hemicelluloses prior to decay testing has been suggested as potential cause for an enhanced resistance of TM-wood in laboratory decay tests in a number of studies (Hakkou et al. 2006; Rowell et al. 2009). Hemicelluloses are easily degradable not only by heat, but also by decay fungi and, thus, are the primary nutrient source at the initial stage of decay (Zabel and Morrell 1992). However, Ringman et al. (2014) argued that both, the non-enzymatic decay by the Fenton's reaction as well as the expression of cellulases, do not require the presence of hemicelluloses, thus, the fungi will degrade the cellulose instead. Although this argumentation seems valid, it neglects a possible decrease in the decay rate when the amount of easily degradable hemicelluloses decreases, while the amounts of lignin and less accessible crystalline cellulose increase. Therefore, it is difficult to separate the effect caused by changes in wood composition from other inhibitory effects based on the mass loss generated during decay testing.

Differences in the mass loss by R. placenta as a function of the mass loss by HT (Fig. 5c), or as a function of the amount of hemicellulose sugars after HT (Fig. 5d) show that the removal of hemicelluloses was not the only factor in reducing the decay rate. TM caused a continuous decrease in the mass loss by $R$. placenta until reaching a mass loss of $2.5 \%$ even though more than $50 \%$ of the hemicelluloses were still present after TM. In contrast, the mass loss by $R$. placenta of HWE-wood decreased only until reaching hemicellulose contents of less than $80 \%$ of the reference or a mass loss by HT of ca. $9 \%$. Beyond these thresholds, the mass loss by $R$. placenta remained in the range between 16.8 and $17.7 \%$ even when the amount of hemicelluloses decreased to ca. $30 \%$ of the reference value.

A better estimate for an actual decay inhibition that is not caused by the preceding removal of hemicelluloses is the cumulative mass loss after HT and decay (Fig. 5b). The continuous increase in the cumulative mass loss caused by HT and $R$. placenta with increasing HWE temperatures suggests that the fungal decay mostly continues the decomposition caused by HWE without any inhibition. A cumulative mass loss of more than $43 \%$ was reached after HWE at $170{ }^{\circ} \mathrm{C}$, which exceeds the mass loss of the reference samples $(24.4 \%)$ notably. In contrast, no increase in the cumulative mass loss was recorded after TM. Instead, a small but gradual decrease was recorded for TM temperatures up to $215^{\circ} \mathrm{C}$ and a clear decrease in the cumulative mass loss was evident for a TM temperature of $230{ }^{\circ} \mathrm{C}$. This evidences an actual decay inhibition by TM that is not solely related to chemical composition changes.

The gravimetric measurements after the decay test were validated by chemical composition analyses (Table 1). For the reference samples, the increase in lignin content to $140 \%$ and the decrease in the content of the different sugars to contents between 38\% (mannose) and 90\% (glucose) of the initial content are in line with a typical brown-rot decay. After fungal decay, all HWE-wood samples had a higher lignin content than TM-wood samples. A clear difference between the HT techniques was also observed for the mannose content after the decay test. The mannose content decreased gradually for HWE-wood, but increased with increasing TM temperature, even beyond the reference value. It should be noted, however, that the total content of wood constituents deviates from $100 \%$, particularly for sample groups with a high mass loss by $R$. placenta. Presumably, fungal biomass
Table 1 Chemical composition of the wood samples after 16 weeks of incubation with Rhodonia placenta

\begin{tabular}{clllllllll}
\hline Treatment & Lig & Glu & Ara & Rha & Gal & Xyl & Man & Ext & Ash \\
\hline $\begin{array}{l}\text { Reference } \\
\mathrm{HT}_{\text {dry }}\end{array}$ & $36.0(140)$ & $42.4(90)$ & $0.9(52)$ & $0.1(7)$ & $0.6(41)$ & $4.4(75)$ & $4.9(38)$ & 1.6 & 0.5 \\
$185^{\circ} \mathrm{C}$ & $37.5(146)$ & $42.5(91)$ & $0.7(43)$ & $0.1(6)$ & $1.4(89)$ & $3.8(65)$ & $6.1(47)$ & 0.9 & 1.4 \\
$200{ }^{\circ} \mathrm{C}$ & $35.5(138)$ & $43.7(93)$ & $0.6(38)$ & $0.1(4)$ & $1.2(79)$ & $3.6(61)$ & $7.3(57)$ & 1.7 & 0.3 \\
$215^{\circ} \mathrm{C}$ & $39.2(152)$ & $44.8(96)$ & $0.5(28)$ & $0.1(3)$ & $0.9(59)$ & $3.2(54)$ & $7.4(58)$ & 2.6 & 0.3 \\
$230^{\circ} \mathrm{C}$ & $36.8(143)$ & $50.6(108)$ & $0.2(12)$ & - & $0.8(54)$ & $2.6(44)$ & $7.6(59)$ & 0.2 & 1.3 \\
$\mathrm{HT}_{\text {wet }}$ & & & & & & & & & \\
$125^{\circ} \mathrm{C}$ & $40.8(158)$ & $38.8(83)$ & $0.4(25)$ & $0.1(4)$ & $1.2(76)$ & $3.1(52)$ & $4.2(32)$ & 1.7 & 0.2 \\
$140^{\circ} \mathrm{C}$ & $40.8(158)$ & $44.6(95)$ & $0.3(16)$ & - & $1.0(62)$ & $3.1(52)$ & $4.6(36)$ & 1.4 & 0.2 \\
$155^{\circ} \mathrm{C}$ & $41.4(161)$ & $46.4(99)$ & $0.2(10)$ & - & $0.6(36)$ & $2.4(40)$ & $3.4(26)$ & 2.2 & 0.2 \\
$170{ }^{\circ} \mathrm{C}$ & $45.6(177)$ & $44.6(95)$ & $0.1(7)$ & - & $0.3(21)$ & $1.9(31)$ & $1.7(13)$ & 4.2 & 0.2 \\
\hline
\end{tabular}

Amounts are given in weight- $\%$. The values in parentheses show the relative amounts with the reference value before the decay test set to $100 \%$ for each wood constituent

Lig lignin, Glu glucose, Ara arabinose, Rha rhamnose, Gal galactose, Xyl xylose, Man mannose, Ext extractives 
(i.e. chitin) in the wood contributed to the sample mass, but became soluble by the acid-catalyzed hydrolysis applied during the composition analysis. Thereby, the percentages of wood constituents may be underestimated to some extent for samples that contained a larger amount of fungal biomass. To compensate for such bias, the contents of hemicelluloses and glucose were related to the respective lignin content. The differences in these ratios before and after decay give an indication of the loss of hemicelluloses and glucose by the decomposition by R. placenta (Fig. 6). As an example, a $\Delta \mathrm{Hem} / \mathrm{Lig}$ ratio of zero would indicate no change in the hemicelluloses content during the incubation with $R$. placenta, while a ratio above zero would indicate a loss in hemicelluloses by fungal decay.

In order to compare the two HT techniques, the $\Delta \mathrm{Hem} /$ Lig ratio and the $\Delta$ Gluc/Lig ratio are shown as a function of the mass loss by HT (Fig. 6a and c) and as a function of the hemicellulose content after HT (Fig. 6b and d). The $\Delta \mathrm{Hem} /$ Lig ratio and the $\Delta$ Gluc/Lig ratio both decreased after HT. While it seems trivial that the loss in hemicelluloses during decay decreases when hemicelluloses have already been removed by HT, a further decrease in the $\Delta \mathrm{Hem} / \mathrm{Lig}$ and $\Delta$ Gluc/Lig ratio for TM-wood compared to HWE-wood is also noted when shown as a function of the mass loss or the hemicellulose content after HT. This may indicate that factors other than the preceding thermal removal of hemicelluloses reduced the fungal decay of TM wood additionally.
For HWE-wood, the $\Delta$ Gluc/Lig ratio remained above 0.7 even at high levels of mass loss or hemicellulose removal, which was similar to the change in the mass loss by $R$. placenta shown in Fig. $5 \mathrm{c}$ and d. In contrast, a $\Delta$ Gluc/Lig ratio near zero after $\mathrm{TM}$ at $230{ }^{\circ} \mathrm{C}$ indicates that no cellulose was degraded by the fungi.

In agreement with previous studies on the fungal decay of modified wood (Rapp et al. 2008; Thybring 2013; Thybring et al. 2018), the present comparison of TM- and HWE-wood suggests that the prevention of fungal decay in laboratory tests is closely linked to the reduction in MC and swelling. The availability of water is a prerequisite for fungal decay, although some studies evidence that fungal decay might not require free water in the void structure of wood near fiber saturation (Griffin 1977; Viitanen 2009; Meyer and Brischke 2015). Recently, it was suggested that the decay resistance of chemically and thermally modified wood is caused by an inhibition of the transport of degradation agents through the cell wall (Zelinka et al. 2016; Hunt et al. 2018). The reduced MC of modified wood may prevent the formation of a continuous network of cell wall water that builds a pathway system for the diffusion of ions and other degradation agents emitted by the fungi (Zelinka et al. 2016; Thybring et al. 2018).

The differences in decay resistance between TM and HWE-wood are in agreement with the hypothesis of a transport-inhibition by the delay or the prevention of reaching a threshold MC. The additional swelling restraint of the
Fig. 6 Differential hemicellulose to lignin ratio (a and $\mathbf{b}$ ) and differential glucose to lignin ratio (c and $\mathbf{d})$ as a function of the mass loss by heat-treatment $(\% ; \mathbf{a}$ and $\mathbf{c})$ and the amount of hemicelluloses after heat-treatment ( $\%$ of reference; $\mathbf{b}$ and $\mathbf{d}$ )
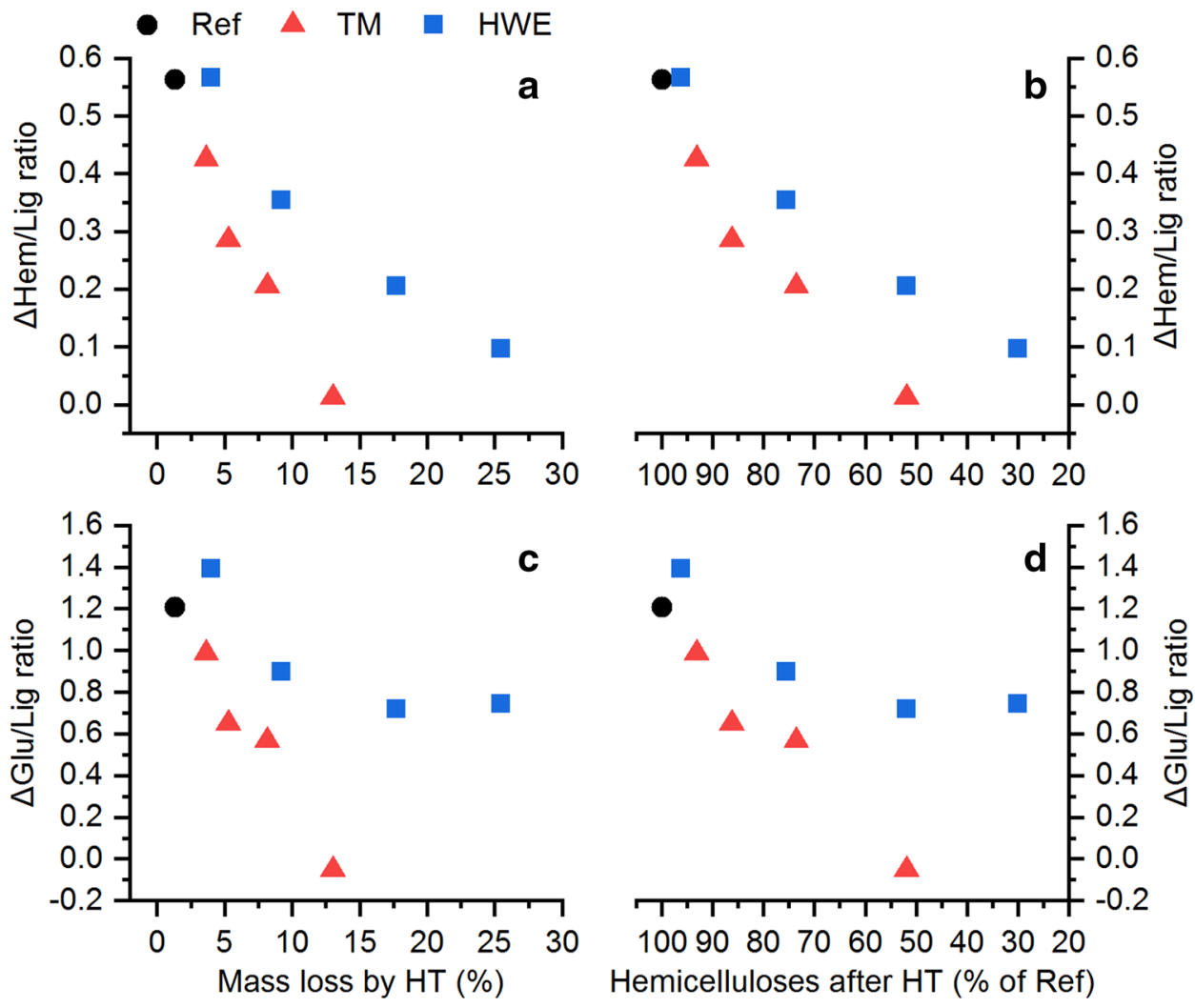
wood created during TM, which is evidenced by the MC and swelling data, may hinder the formation of an interconnected pathway for degradation agents and is a likely cause for the higher decay resistance of TM-wood. In contrast, the less effective reduction in $\mathrm{MC}$ and the increase in swelling by HWE may cause fewer disruptions for the transport of solutes through the water swollen cell wall.

However, the effect of a reduced water swollen porosity may not be limited to a decrease in the rate of transport of solutes. Besides enabling the transport for degradation agents, a larger water swollen cell wall porosity also increases the surface area that is accessible to degradation agents emitted by the fungi. Even if the diffusion rates of degradation agents remained constant, a larger accessibility of degradable wood constituents would increase the rate at which mass loss by fungal decay occurs. The role of the accessible surface area provides an explanation why the mass loss by $R$. placenta does not further decrease at elevated HWE temperatures, but remains nearly constant despite a further reduction in hygroscopicity. Removing cell wall matrix polymers that surround the cellulose microfibrils during HWE may enhance the accessibility of the cellulose for degradation agents when a swelling restraint by crosslinking is not achieved. The chemical composition analysis showed indeed that the constant mass loss by $R$. placenta at elevated HWE temperatures was not caused by a lower reduction in the $\Delta \mathrm{Hem} / \mathrm{Lig}$ ratio, but a nearly constant $\Delta \mathrm{Glu} / \mathrm{Lig}$ ratio. This is in line with an improved enzymatic digestibility of cellulose in Tamarix ramosissima wood after HWE that was explained by an increased surface area and pore volume of the wood powders (Xiao et al. 2013).

It should be noted that the recorded swelling of the samples might underestimate the actual water-swollen porosity of heat-treated wood. This is because some of the pores created by the removal of cell wall constituents may remain open after drying without causing a reduction in dry dimensions. Such an effect was noticed by a reduction in cell wall density that was measured by mercury intrusion porosimetry for TM- and HWE-wood in a previous study (Altgen et al. 2018b). However, the data did not suggest a systematic difference in the cell wall density between TM- and HWEwood when compared as a function of the mass loss by HT.

\section{Conclusion}

HWE removed hemicelluloses effectively, thereby reaching a similar mass loss range at much lower treatment temperatures than TM. The removal of hemicelluloses before the laboratory decay test reduced the mass loss caused by $R$. placenta within 16 weeks of incubation. However, an increasing cumulative mass loss by thermal degradation and decay was recorded after HWE. This indicated that $R$. placenta continued the decomposition of carbohydrates by HWE without inhibition. TM was much more effective in reducing decay by $R$. placenta than HWE. This was assigned to an enhanced cross-linking of the cell wall matrix caused by TM, which reduced the water-swollen porosity of the wood cell wall. Thereby, the transport of degradation agents through the cell wall was disrupted and/or the accessibility of wood constituents was reduced. HWE did not induce such a swelling restraint, thus, a high mass loss by $R$. placenta was recorded even when large quantities of hemicelluloses were removed prior to decay testing.

Acknowledgements Open access funding provided by Aalto University. Financial support from the Academy of Finland (Decision No. 309881) and from the South Savo Regional Council of the European Regional Development Fund (Project Code A7389) is acknowledged. We thank Sari Seppänen from the Environmental Sciences Laboratory for arranging the decay test.

\section{Compliance with ethical standards}

Conflict of interest There are no conflicts of interest to declare.

Open Access This article is licensed under a Creative Commons Attribution 4.0 International License, which permits use, sharing, adaptation, distribution and reproduction in any medium or format, as long as you give appropriate credit to the original author(s) and the source, provide a link to the Creative Commons licence, and indicate if changes were made. The images or other third party material in this article are included in the article's Creative Commons licence, unless indicated otherwise in a credit line to the material. If material is not included in the article's Creative Commons licence and your intended use is not permitted by statutory regulation or exceeds the permitted use, you will need to obtain permission directly from the copyright holder. To view a copy of this licence, visit http://creativecommons.org/licenses/by/4.0/.

\section{References}

Altgen M, Uimonen T, Rautkari L (2018a) The effect of de- and repolymerization during heat-treatment on the mechanical behavior of Scots pine sapwood under quasi-static load. Polym Degrad Stab 147:197-205

Altgen M, Willems W, Hosseinpourpia R, Rautkari L (2018b) Hydroxyl accessibility and dimensional changes of Scots pine sapwood affected by alterations in the cell wall ultrastructure during heat-treatment. Polym Degrad Stab 152:244-252

Ammer U (1963) Untersuchungen über das Wachstum von Rotstreifepilzen in Abhängigkeit von der Holzfeuchtigkeit. Forstwiss Cent 82:360-391

Arantes V, Milagres AMF, Filley TR, Goodell B (2011) Lignocellulosic polysaccharides and lignin degradation by wood decay fungi: the relevance of nonenzymatic Fenton-based reactions. J Ind Microbiol Biotechnol 38:541-555

Arantes V, Jellison J, Goodell B (2012) Peculiarities of brown-rot fungi and biochemical Fenton reaction with regard to their potential as a model for bioprocessing biomass. Appl Microbiol Biotechnol 94:323-338

CEN/TS 15083-1:2005 (2005) Durability of wood and wood-based products. Determination of the natural durability of solid wood 
against wood-destroying fungi, test methods. Basidiomycetes. CEN-European Committee for Standardization, Brussels, Belgium

Cohen R, Jensen KA, Houtman CJ, Hammel KE (2002) Significant levels of extracellular reactive oxygen species produced by brown rot basidiomycetes on cellulose. FEBS Lett 531:483-488

Ebringerová A, Heinze T (2000) Xylan and xylan derivatives-biopolymers with valuable properties, 1 . Naturally occurring xylans structures, isolation procedures and properties. Macromol Rapid Commun 21:542-556

Flournoy DS, Paul JA, Kirk TK, Highley TL (1993) Changes in the size and volume of pores in sweetgum wood during simultaneous rot by Phanerochaete chrysosporium Burds. Holzforschung 47:297-301

Garrote G, Domínguez H, Parajó JC (1999) Hydrothermal processing of lignocellulosic materials. Holz Roh Werkst 57:191-202

Goodell B, Jellison J, Liu J, Daniel G, Paszczynski A, Fekete F, Krishnamurthy S, Jun L, Xu G (1997) Low molecular weight chelators and phenolic compounds isolated from wood decay fungi and their role in the fungal biodegradation of wood. J Biotechnol 53:133-162

Goodell B, Yuan Z, Seong K, Kafle K, Eastwood D, Daniel G, Jellison J, Yoshida M, Groom L, Pingali SV, O’Neil H (2017) Modification of the nanostructure of lignocellulose cell walls via a non-enzymatic lignocellulose deconstruction system in brown rot wood-decay fungi. Biotechnol Biofuels 10:179

Griffin DM (1977) Water potential and wood-decay fungi. Annu Rev Phytopathol 15:319-329

Hakkou M, Pétrissans M, Gérardin P, Zoulalian A (2006) Investigations of the reasons for fungal durability of heat-treated beech wood. Polym Degrad Stab 91:393-397

Hammel KE, Kapich AN, Jensen KA, Ryan ZC (2002) Reactive oxygen species as agents of wood decay by fungi. Enzyme Microb Technol 30:445-453

Hill CAS (2006) Wood modification: chemical, thermal and other processes. Wiley, Chichester

Hosseinaei O, Wang S, Enayati AA, Rials TG (2012) Effects of hemicellulose extraction on properties of wood flour and woodplastic composites. Compos Part A Appl Sci Manuf 43:686-694

Hosseinpourpia R, Mai C (2016) Mode of action of brown rot decay resistance of thermally modified wood: resistance to Fenton's reagent. Holzforschung 70:691-697

Hunt CG, Zelinka SL, Frihart CR, Lorenz L, Yelle D, Gleber S-C, Vogt S, Jakes JE (2018) Acetylation increases relative humidity threshold for ion transport in wood cell walls-a means to understanding decay resistance. Int biodeterior Biodegrad 133:230-237

Hyde SM, Wood PM (1997) A mechanism for production of hydroxyl radicals by the brown-rot fungus Coniophora puteana: fe(III) reduction by cellobiose dehydrogenase and $\mathrm{Fe}(\mathrm{II})$ oxidation at a distance from the hyphae. Microbiology 143:259-266

Kemppainen K, Inkinen J, Uusitalo J, Nakari-Setälä T, Siika-aho M (2012) Hot water extraction and steam explosion as pretreatments for ethanol production from spruce bark. Bioresour Technol 117:131-139

Kirk TK, Highley TL (1973) Quantitative changes in structural components of conifer woods during decay by white- and brown-rot fungi. Phytopathology 63:1338-1342

Kirker G, Zelinka S, Gleber S-C, Vine D, Finney L, Chen S, Hong YP, Uyarte O, Vogt S, Jellison J, Goodell B, Jakes JE (2017) Synchrotron-based X-ray fluorescence microscopy enables multiscale spatial visualization of ions involved in fungal lignocellulose deconstruction. Sci Rep 7:41798

Li T, Cheng D, Avramidis S, Wålinder MEP, Zhou D-g (2017) Response of hygroscopicity to heat treatment and its relation to durability of thermally modified wood. Constr Build Mater 144:671-676

Metsä-Kortelainen S, Viitanen H (2009) Decay resistance of sapwood and heartwood of untreated and thermally modified Scots pine and Norway spruce compared with some other wood species. Wood Mater Sci Eng 4:105-114

Meyer L, Brischke C (2015) Fungal decay at different moisture levels of selected European-grown wood species. Int biodeterior Biodegrad 103:23-29

Militz H, Altgen M (2014) Processes and properties of thermally modified wood manufactured in Europe. In: Schultz TP, Goodell B, Nicholas DD (eds) Deterioration and protection of sustainable biomaterials. ACS Symposium Series 1158, Chapter 16. American Chemical Society, New York, pp 269-285

Mohareb A, Sirmah P, Pétrissans M, Gérardin P (2012) Effect of heat treatment intensity on wood chemical composition and decay durability of Pinus patula. Eur J Wood Prod 70:519-524

Pelaez-Samaniego MR, Yadama V, Garcia-Perez T, Lowell E, Amidon $\mathrm{T}$ (2014) Effect of hot water extracted hardwood and softwood chips on particleboard properties. Holzforschung 68:807-815

Rapp AO, Brischke C, Welzbacher CR, Jazayeri L (2008) Increased resistance of thermally modified Norway spruce timber (TMT) against brown rot decay by Oligoporus placenta-study on the mode of protective action. Wood Res-Slovak 53:13-25

Repellin V, Guyonnet R (2005) Evaluation of heat-treated wood swelling by differential scanning calorimetry in relation to chemical composition. Holzforschung 59:28-34

Ringman R, Pilgård A, Brischke C, Richter K (2014) Mode of action of brown rot decay resistance in modified wood: a review. Holzforschung 68:239-246

Ringman R, Pilgård A, Kölle M, Brischke C, Richter K (2016) Effects of thermal modification on Postia placenta wood degradation dynamics: measurements of mass loss, structural integrity and gene expression. Wood Sci Technol 50:385-397

Rowell RM, Ibach RE, McSweeny J, Nilsson T (2009) Understanding decay resistance, dimensional stability and strength changes in heat treated and acetylated wood. In: Proceedings of the 4th European Conference on Wood Modification, Stockholm, Sweden, pp 489-502

Sattler C, Labbé N, Harper D, Elder T, Rials T (2008) Effects of hot water extraction on physical and chemical characteristics of oriented strand board (OSB) wood flakes. Clean-Soil Air Water 36:674-681

Sella Kapu N, Trajano HL (2014) Review of hemicellulose hydrolysis in softwoods and bamboo. Biofuel Bioprod Biorefin 8:857-870

Sluiter A, Hames B, Ruiz R, Scarlata C, Sluiter J, Templeton D, Crocker D (2012) Determination of structural carbohydrates and lignin in biomass. National Renewable Energy Laboratory (NREL), Golden (NREL/TP-510-42618)

Stienen T, Schmidt O, Huckfeldt T (2013) Wood decay by indoor basidiomycetes at different moisture and temperature. Holzforschung 68:9-15

Strømdahl K (2000) Water sorption in wood and plant fibres. PhD thesis. Technical University of Denmark, Lyngby, Denmark

TAPPI 211 om-02 (2002) Ash in wood, pulp, paper and paperboard: combustion at $525{ }^{\circ} \mathrm{C}$. Technical Association of the Pulp and Paper Industry, Atlanta

Thybring EE (2013) The decay resistance of modified wood influenced by moisture exclusion and swelling reduction. Int Biodeter Biodegr 82:87-95

Thybring EE, Kymäläinen M, Rautkari L (2018) Moisture in modified wood and its relevance for fungal decay. iForest 11:418-422

Tjeerdsma BF, Boonstra M, Pizzi A, Tekely P, Militz H (1998) Characterisation of thermally modified wood: molecular reasons for wood performance improvement. Holz Roh Werkst 56:149-153 
Viitanen HA (2009) Modelling the time factor in the development of brown rot decay in pine and spruce sapwood - the effect of critical humidity and temperature conditions. Holzforschung 51:99-106

Wang Y, Zhang Z, Fan H, Wang J (2018) Wood carbonization as a protective treatment on resistance to wood destroying fungi. Int Biodeter Biodegr 129:42-49

Welzbacher CR, Rapp AO (2007) Durability of thermally modified timber from industrial-scale processes in different use classes: results from laboratory and field tests. Wood Mater Sci Eng 2:4-14

Winandy JE (2017) Relating wood chemistry and strength: part II. Fundamental relationships between changes in wood chemistry and strength of wood. Wood Fiber Sci 49:1-10

Winandy JE, Morrell JJ (1993) Relationship between incipient decay, strength, and chemical composition of Douglas-fir heartwood. Wood Fiber Sci 25:278-288

Xiao LPM, Shi Z-J, Xu F, Sun R-C (2013) Hydrothermal treatment and enzymatic hydrolysis of Tamarix ramosissima: evaluation of the process as a conversion method in a biorefinery concept. Bioresour Technol 135:73-81

Yoon S-H, Van Heiningen A (2008) Kraft pulping and papermaking properties of hot-water pre-extracted loblolly pine in an integrated forest products biorefinery. Tappi J 7:22-27

Zabel RA, Morrell JJ (1992) Wood microbiology. Decay and its prevention. Academic Press, San Diego

Zelinka SL, Ringman R, Pilgård A, Thybring EE, Jakes JE, Richter $K$ (2016) The role of chemical transport in the brown-rot decay resistance of modified wood. Int Wood Prod J 7:66-70

Zhang J, Presley GN, Hammel KE, Ryu J-S, Menke JR, Figueroa M, Hu D, Orr G, Schilling JS (2016) Localizing gene regulation reveals a staggered wood decay mechanism for the brown rot fungus Postia placenta. Proc Natl Acad Sci 113:10968-10973

Publisher's Note Springer Nature remains neutral with regard to jurisdictional claims in published maps and institutional affiliations. 